\title{
CONTENTS
}

Acknowledgments ix

1 Introduction: Contextualizing Reflection

Kathleen Blake Yancey 3

\section{TEACHING AND ASSESSMENT}

2 Reflection: The Metacognitive Move towards Transfer of Learning Anne Beaufort 23

3 Reiterative Reflection in the Twenty-First-Century Writing Classroom: An Integrated Approach to Teaching for Transfer Kara Taczak and Liane Robertson 42

4 The Perils of Standing Alone: Reflective Writing in Relationship to Other Texts

Michael Neal 64

5 Reflecting Practices: Competing Models of Reflection in the Rhetoric of Prior Learning Assessment

Cathy Leaker and Heather Ostman 84

II RELATIONSHIPS: REFLECTION, LANGUAGE, AND DIFFERENCE

6 Reflecting the Translingual Norm: Action-Reflection, ELF, Translation, and Transfer

Bruce Horner 105

7 Theorizing the Reflection Practices of Female Hmong College Students: Is Reflection a Racialized Discourse?

Asao B. Inoue and Tyler Richmond 125

III REFLECTION AND MEDIA

8 From Selfies to Self-Representation in Electronically Mediated Reflection: The Evolving Gestalt Effect in ePortfolios

J. Elizabeth Clark 149 
9 Reflection in Digital Spaces: Publication, Conversation, Collaboration

Naomi Silver 166

\section{REFLECTIVE CONVERSATIONS OUTSIDE THE} WRITING CLASSROOM

10 Toward Defining a Social Reflective Pedagogy for ePortfolios Christina Russell McDonald 203

11 From Apprised to Revised: Faculty in the Disciplines Change What They Never Knew They Knew

Pamela Flash 227

12 Reflective Interviewing: Methodological Moves for Tracing Tacit Knowledge and Challenging Chronotopic Representations

Kevin Roozen 250

V REFLECTION AND GENRE

13 Problematizing Reflection: Conflicted Motives in the Writer's Memo

Jeff Sommers 271

14 Reflection and the Essay

Doug Hesse 288

V I

IN CONCLUSION: REFLECTION AS RHETORICAL

15 Defining Reflection: The Rhetorical Nature and Qualities of Reflection

Kathleen Blake Yancey 303

About the Authors $\quad 321$

Index 325 


\title{
I NTROD UCT ION \\ Contextualizing Reflection
}

\author{
Kathleen Blake Yancey
}

In the summer of 2014, I offered an independent study on reflection to three doctoral students in rhetoric and composition, Bruce Bowles, Joe Cirio, and Erin Workman, each of whom brought reflection-related interests with them to the course. Bruce is very interested in writing assessment, especially response to writing. Joe was conducting a qualitative study inquiring into whether students have enough conceptual knowledge, vocabulary, motivation, and agency to participate in creating scoring guides. Erin brought with her a completed pilot project on transfer of writing knowledge and practice highlighting the role of reflection. The question: in this one-hour graduate course on reflection, what might we read?

Had we asked this question in the 1970s at the beginning of the composing-process movement, the answer would have been short and quick, the readings focusing largely on the cognitive role that reflection plays in writing. In 1979, for example, Sharon Pianko defined reflection behaviorally as the "pauses and rescannings" stimulating "the growth of consciousness in students about the numerous mental and linguistic strategies" entailed in composing and "the many lexical, syntactical, and organizational choices" made during composing (Pianko 1979, 277-78). Pianko's claim also included the idea that reflection, as a practice, distinguished able from "not-so-able" writers. And at about the same time, Sondra Perl (1980) identified two components of reflection, what she called "projection" and "retrospection," "the alternating mental postures writers assume as they move through the act of composing" (389). In brief, the emergent literature on reflection at this moment in composition's history was tightly focused on the mental activities of the composer in the process of composing.

Had we asked this question about readings on reflection in the late 1980s and into the 1990s, however, we would have had a second literature to draw on as well, much of it oriented toward designing reflective 


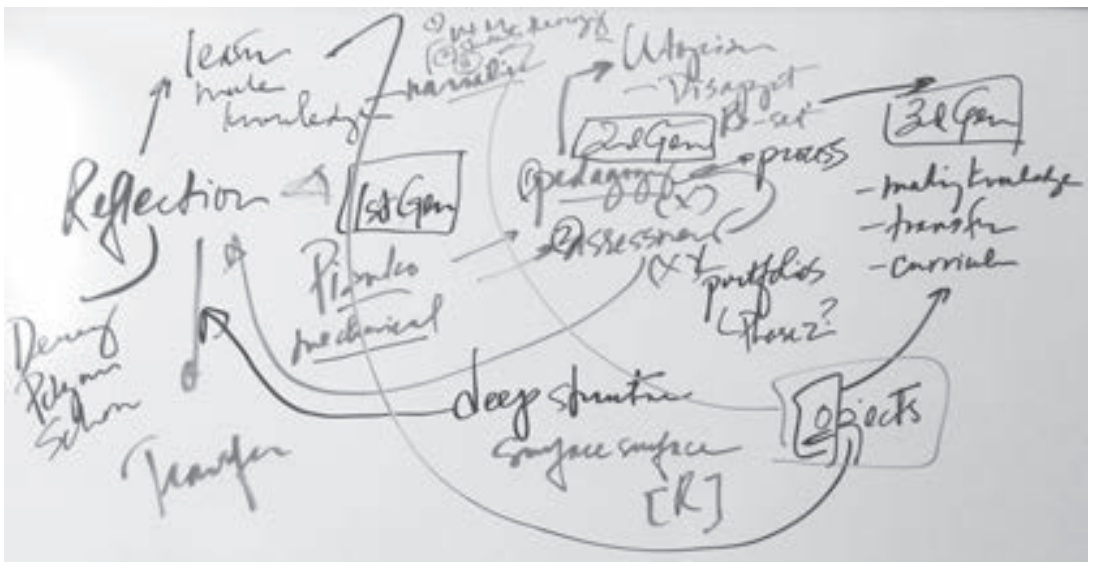

Figure 1.1.

activity to help make students' thinking external, visible, and availablefor both assessment and teaching purposes. Roberta Camp (1992), for example, outlined one use of reflection, for portfolios, explaining how inside a portfolio a student could map the changing shape of a multiply drafted composition in what she called a "biography of a text"; thinking pedagogically, Bill Thelin (1994) explored how responding to writing changes, and doesn't, in the context of a portfolio and its reflection; and Jeff Sommers (1988) created a Writer's Memo allowing students, in a student's words, to go "behind the paper" to describe "the composing process which produced the draft" (77). Interestingly, Sommers (1988) pointed out that the memo assists both student and teacher: in Sommers's view, the memo's intent, like that of many reflective practices developed at this time, was twofold: (1) to elucidate student composing activities in students' own descriptions so as to see what was otherwise invisible and (2) to provide a context for an instructor-student conversation about the draft itself. Likewise, also addressing classroom and assessment contexts, I developed a Schonean-influenced practice-based theory of reflection in writing keyed to three related forms of reflective practice:

reflection-in-action, the process of reviewing and projecting and revising, which takes place within a composing event;

constructive reflection, the process of developing a cumulative, multi-selved, multi-voiced identity, which takes place between and among composing events; and

reflection-in-presentation, the process of articulating the relationships between and among the multiple variables of writing and the writer in a specific context for a specific audience. (Yancey 1998, 200) 
During this time, reflection was also playing a major role in assessment, first in print portfolios and later, of course, in electronic portfolios, with both portfolio models defined as the result of three processes: collecting a range of texts, selecting from among them for a portfolio composition, and reflecting (Yancey 1992) - though the reflecting on whom or what varied. In some models, the reflective text was supposed to provide a narrative of writerly development, in others an account of process or self-assessment, and in still others an introduction to the portfolio itself. Furthermore, as in the case of pedagogical practice, so too in assessment: the role reflection plays in writing assessment has been both conceptualized and reconceptualized. Early in the portfolio movement, for example, Chris Anson (1994) categorized reflection as a secondary text in dialogue with-but mostly in support of - the primary texts of a portfolio. Later, I theorized that reflective texts are primary texts in their own right, though of a different nature than "primary" writing texts, and that the relationship between these two kinds of texts was dialogic and multicontextual, not hierarchical. More recently, Ed White (2005) has suggested that the reflective text can function as a surrogate for the full portfolio in an assessment context, though earlier research such as Glenda Conway's (1994) has suggested that this cover letter is problematic, much more a performance piece than an authentic expression for students, indeed, something of a mask through which to present the best possible student self (89), which makes perfect sense given the stakes. And other research (e.g., Yancey forthcoming) has observed that the Phase 2 portfolio scoring model mistakes one construct, that of argumentative writing, for a different construct, reflective writing. In general, then, during this second period of scholarship in reflection, the field moved beyond descriptions of mental behaviors to develop and theorize new classroom and assessment practices.

Into the twenty-first century, the scholarship on reflection is in a third phase or generation, with the list of readings we might consult now both wide and varied. Seen through Perl's (1980) formation, current interest in reflection is an exercise in both retrospection and prospection, with teachers and scholars returning to earlier practices to revise them, considering those practices in larger contexts for critique and theorizing reflection in new ways and for future use. Jeff Sommers (2011), for example, has revised his Writer's Memos into a semester-long reflective project focused on students' individual and collective beliefs about writing and the ways those beliefs do, and don't, change over the course of a term; Anne Beaufort (2007) has pointed to reflection as a key component supporting transfer of 
writing knowledge and practice; Kara Taczak, Liane Robertson, and I have theorized reflection as part of a new writing curriculum we call Teaching for Transfer (TFT) (Yancey, Robertson, and Taczak 2014), and Cathy Leaker and Heather Ostman have documented the epistemological nature of reflection, demonstrating how reflection contributes to and provides evidence of knowledge developed experientially (Leaker and Ostman 2010). During this time, there has also been a different kind of return to the past, with scholars expressing concerns and raising questions. Tony Scott (2005), for instance, has raised red flags about what he perceives as a Foucaultian dimension of reflection; other scholars have questioned what they see as a presumed relationship between reflection and the unified self-or the possibility of such a self-with reflection serving as something of a flashpoint. Thus, while scholars like Pat Belanoff (2001) contend that reflection "can enable the reconstituting-if only momentarily-of a unified self, which certainly enables one to act more effectively" (421), Glenda Conway (1994) and Kimberly Emmons (2003), taking another tack, agree with Julie Jung (2011) that, in Jung's formation, reflective writing tends "to legitimize liberal constructions of the writer as a single, unified self" (629) and that "reflective writing pedagogy, which aims to help student-writers assert authority as writers . . reinforc [es] some students' sense of themselves as 'only' students" (642; italics in original).

In higher education more generally, however, both reflection and metacognition are increasingly identified as important for learning. In writing studies, reflection has been the key term, while in highereducation contexts, reflection and metacognition are often used interchangeably. As constructs, reflection and metacognition have some overlap, but they also are assigned different attributes and roles in supporting learning. In How Learning Works (2010), for example, Susan A. Ambrose, Michael W. Bridges, Michele DiPietro, Marsha C. Lovett, and Marie K. Norman define metacognition and reflection conventionally: the first, metacognition, as thinking about thinking associated with planning, self-monitoring, and self-regulation; the second, reflection, as oriented to self-assessment activity occurring at the end of a learning cycle, though capable of prompting a new one.

Researchers have proposed various models to describe how learners ideally apply metacognitive skills to learn and perform well (Butler 1998; Pintrich 2000; Winne and Hadwin 1998). Although these models differ in their particulars, they share the notion that learners need to engage in a variety of processes to monitor and control their learning (Zimmerman 2000). Moreover, because the processes of monitoring 
and controlling mutually affect each other, these models often take the form of a cycle. Learners

- assess the task at hand, taking into consideration the task's goals and constraints;

- evaluate their own knowledge and skills, identifying strengths and weaknesses;

- plan their approach in a way that accounts for the current situation;

- apply various strategies to enact their plan, monitoring their progress along the way;

- reflect on the degree to which their current approach is working so that they can adjust and restart the cycle as needed. (Ambrose et al. 2010, 91-92)

Most theorists agree with this definition in that metacognition includes self-monitoring, but the role of reflection in learning, or coming to know, has received less attention from scholars in cognitive psychology. Others interested in learning writ large have focused on reflection: notable among them are John Dewey (1910) and Donald Schon (1987). Drawing on both Dewey and Schon in accounting for reflection more fully, for example, Naomi Silver (2013) agrees with the general definition of metacognition while widening reflection's scope to include "conscious exploration of one's own experiences" (1). The construct of reflection, she says, "as theorized by John Dewey is broader in its scope, and also more rigorous" (6). In his landmark book How We Think, Dewey defines "reflective thought" as "active, persistent, and careful consideration of any belief or supposed form of knowledge in light of the grounds that support it, and the further conclusions to which it tends" (Dewey 1910, 6; emphasis in original). Deweyan reflection is more sustained than a general stocktaking, then, and perhaps closer to the much broader concept of critical thought itself. Reflection, for him, constitutes a meticulous process of evidence and implication seeking, with the aim not only of understanding more fully by means of creating connections and relationships within experiences, but also of transforming experience and one's environment as a result (Dewey 1910, 1916).

In contrast, Donald Schon's approach, as Silver (2013) observes, is located more in professional practice, which allows him "to define a framework that describes how professionals' tacit knowledge of their work may be more deliberately mobilized and taught to learners in the field, ultimately resulting in a curriculum for a 'reflective practicum' to form the core of professional training" (Schon 1987).

As important for both theorists of reflection is the role of a real problem in a context of uncertainty. As Silver (2013) explains, because the 
thinker feels "discomfort or uncertainty, what Dewey calls 'a forked-road situation, a situation which is ambiguous," there is "'a dilemma, which proposes alternatives"” (Dewey 1916, quoted in Silver 2013, 11). This dilemma, according to Dewey, is fundamental. Likewise, according to Silver, Schon identifies a "confrontation with confusion or ambiguity" as the exigence for reflective thinking and the opportunity for "a professional practitioner's tacit knowledge [to be] challenged," (8) the challenge then prompting the practitioner to "name" and "frame" the problem and to begin to make explicit the tacit knowledge aligning theory and practice.

As A Rhetoric of Reflection demonstrates, the Deweyian-Schonian construct of reflection as a synthetic knowledge-making activity keyed to uncertainty and ambiguity is critical for scholars in writing studies focusing on reflection, as it is for scholars currently studying learning in many other contexts, including general learning contexts; preprofessional and professional contexts ranging from medicine and education to engineering; and assessment contexts, those including electronic portfolios. The research on how students learn, for example, compiled in the National Research Council volume How People Learn (Bransford, Pellegrino, and Donovan 2000) and documented in more reflectionspecific studies like the Harvard Business School's recent working paper "Learning by Thinking: How Reflection Aids Performance," points to reflection-defined in "Learning by Thinking" as an "intentional attempt to synthesize, abstract, and articulate the key lessons taught by experience" (Di Stefano et al. 2014, 3)-as critical in helping learners secure their learning. The theory outlined in "Learning by Thinking" is particularly interesting. Building on Dewey's concept of learning by doing (1933), Giada Di Stefano, Francesca Gino, Gary Pisano, and Bradley Staats make two provocative, empirically validated arguments (Di Stefano et al. 2014). First, for learning to take hold, we must "do," engaging in experience, as Dewey said, but we must also think, or reflect, on that learning for it to make sense, and when we do, our performance improves. Second, such reflecting contributes to self-efficacy precisely because it helps us understand that we have learned (even if not always successfully); how we have learned; and how we might continue to learn. Likewise, in numerous professionsincluding medicine (e.g., Gawande 2002), teaching (Brookfield 1995; also see Pamela Flash's chapter in this volume), and engineering (as demonstrated in Virginia Tech's NSF-funded engineering project employing reflective practice to support the development of engineering faculty and researchers)-reflection provides a mechanism for 
professional development, for professional practice, and for the making of knowledge. The same is true for assessment: drawing on and synthesizing research sponsored by the Inter/National Coalition for Electronic Portfolio Research, for example, I have theorized reflection's potential to help students not only to invent the university, in David Bartholomae's telling phrase, but also, and rather, to reinvent it (Yancey 2009), a point I return to below.

In the context of large-scale national assessment efforts, reflection is also playing a role, most notably as one of the indicators of student engagement in the National Survey of Student Engagement (NSSE 2014), which has been identified as one of the (few) measures of student progress acceptable to the federal government and whose results consistently correlate with student retention and graduation. More specifically, linking reflective learning to integrative learning and to writing, NSSE results show that reflective and integrative learning "requires students to personally connect with the course material by considering prior knowledge and experiences, other courses, and societal issues. Students must take into account the diverse perspectives of others as well as their own views while examining the views of others. Reflective and integrative learning is characteristic of students who engage in deep approaches to learning" ("A Fresh Look at Student Engagement" 2013). As explained here, then, deep-learning pedagogical approaches supporting student learning as articulated in reflective writing have now been documented as fundamental to students' learning and to their advancement in college.

In other words, during the last four decades, understanding of reflection has widened and deepened in writing studies, in learning theory, in the professions, in assessment contexts, and across higher education. Moreover, reflection in writing studies, seen through the conceptual lens of a generation, seems to be entering a third generation. What we might call the first generation of reflection, taking its cue from more generalized work on metacognition and thinking, focused on identifying and describing internal cognitive processes assumed to be part of composing. The second generation, operating in both classroom and assessment scenes, developed mechanisms for externalizing reflection, making it visible and thus explicitly available to help writers. The emerging work of the third generation in reflection-which in writing studies has included critiques of earlier work but has focused largely on revisions of earlier work, on conceptual advances, and on an increasing appreciation of reflection in the higher-education community-creates an exigence for the essays collected here. 
Perhaps most important among the work of this third generation on reflection in writing studies is our increasing appreciation of the epistemological value of reflection, of its ability to help us make new meanings, of its rhetorical power. Earlier, I referred to the distinction between a Bartholomae-ian inventing a university and a student's reinventing one, a distinction that helps us understand reflection as rhetorical. More specifically, drawing on work in portfolios, I distinguished between students' invention of our university, which is basically their replication of the given, and their reinvention of our university, which of course changes it in ways we cannot control.

In 1985, rhetoric and composition scholar David Bartholomae coined the expression inventing the university to explain the basic task of the postsecondary student aspiring to success: "He must learn to speak our language." In connecting our language and students' invention of the university, Bartholomae highlighted a need for students to accommodate to and assimilate into $u s$, into our institutions. Such accommodation doesn't always succeed, however, as we see in student retention and graduation rates, and as we see all too often in disengaged students who are dropouts in waiting. (Yancey 2009, 15-16)

I also pointed to portfolios as a site of such reinvention and to reflection as the practice supporting it, noting the complementary roles that portfolios and reflection play in this process, with portfolios providing a site for multiple curricula and "reflection [providing] a specific opportunity to see each [curriculum], to talk across them, to connect them, to trace the contradictions among them, to create a contingent sense of them. In this sense of reflection, it is itself a site of invention, a place to make new knowledge and to shape new selves, and in so doing, re-invent the university as well." (16)

Of course, as we have seen and as the chapters here demonstrate, reflection operates outside portfolios as well; still, the distinction between students inventing our university and their reinventing it exemplifies the epistemology of reflection and its nature as a Bakhtinian practice. In other words, I theorized reflection as a Bakhtinian rhetorical exercise through which one engages with the cultural, to draw from it and give back to it in an exercise of meaning making at once both individual and social. Such reflective meaning as it works in language, Bakhtin says, is possible

only when the speaker populates it with his own intentions, his own accent, when he appropriates the word, adapting it to his own semantic and expressive intention. Prior to this moment of appropriation, the word does not exist in a neutral and impersonal language (it is not, after all, 
out of a dictionary that the speaker gets his words!), but rather it exists in other people's mouths, in other people's contexts, serving other people's intentions: it is from there that one must take the word, and make it one's own. (Bakhtin 1981, 293-94)

Through the practice of reflection, we draw on what is culturally known and infuse, interweave, integrate it with what we as individuals know-cognitively, affectively, and socially-to make a new knowledge that draws from the extant but is not a replication of it, that is, instead, unique, a knowledge only each one of us can make as it is in dialogue with what is. Not least, that new knowledge, collectively enacted, changes the very cultures situating reflective practice. More generally, then, what we are learning in this third generation of work in and on reflection is that it offers much more to writers and teachers of writers than has previously been assumed.

What that much more might be is the focus of $A$ Rhetoric of Reflection. Reading across the chapters, we can identify at least three understandings of reflection shared by the authors here. First, to think of reflection only or exclusively as a mechanism for evaluation is to waste its potential: reflection can assist with assessment, certainly, but its larger value is linked to supporting writers in a myriad of ways as they develop both writing knowledge and practice. Second, in using reflection in our instruction, we have focused on pedagogy without attending as closely to curricular and extracurricular considerations. What, we are now asking, would a curriculum in reflection look like? Perhaps more important, what would a curriculum in reflection for writing look like? What reflective extracurricular activities help us understand student writing development and create more facilitative curricula? Third, our current approach to reflection is more nuanced and considered; we are developing research activities seeking to document, with the help of students and faculty, how it fosters an explicitness about learning and supports all of us in articulating and claiming what we know. Increasingly, we are coming to understand the role of community in this process. Put as a general proposition, the stand-alone individual letter of reflection has become a portal for a more robust conception of reflection, one directly connected to supporting student learning and contributing to a more humane assessment.

And not surprisingly, in this process of rethinking, reconceptualizing, and reapplying what we know about reflection, the authors here are raising new questions about it and the contexts of its use-and usefulness. Thinking in terms of transfer of writing knowledge and practice, for example, Anne Beaufort speaks to the potential of reflection as a 
mechanism of support, while Liane Robertson and Kara Taczak articulate a theory of reflection developed in concert with the Teaching for Transfer writing curriculum. What is the role of reflection, these teachers ask, in students' transfer of knowledge and practice, and how do we design such a role into curriculum? Drawing on his years of teaching with reflection, Jeff Sommers asks about how we need to situate reflection as a pedagogical tool within the curriculum. Given the relationship of practice to theory, how do we contextualize the Writer's Memo? Elizabeth Clark, Christina McDonald, and Naomi Silver each raise several questions related to electronically mediated reflection and the affordances it can offer students. What forms, for example, does multimedia reflection take? What do we gain in a reflection linked to multimedia that may not be available in print? What difference do modality and medium make for students and for learning? Michael Neal includes teaching in his consideration of reflection, but he links it to assessment: how, he asks, does reflection operate in teaching and assessment contexts, and can these two scenes for reflection be complementary?

Approaching the question of the relationship between assessment and reflection from a different perspective, Cathy Leaker and Heather Ostman move outside the classroom to consider how reflection contributes to the making of knowledge, especially in the context of prior learning assessment (PLA). The purpose of PLA is to allow students to earn college credit for experience: in their earlier work on PLA, Leaker and Ostman carefully documented the ways that through reflection students can articulate knowledge that can be credentialed through PLA. Here, they widen their focus to ask, how can PLA and other experientially based credit-awarding practices be linked to epistemology, equity, and social justice?

Thinking of reflection as a kind of conversation, Pamela Flash and Kevin Roozen explain the reflective conversations they have staged, Pamela with faculty in the context of a writing across the curriculum program and Kevin in the context of learning from a student about her literacy trajectory. How, both ask, does a reflective conversation allow participants to explicate tacit knowledge? Taking a very different tack, Bruce Horner asks how reflection might function as an inherent resource for all language learners, while Asao Inoue and Tyler Richmond raise questions about the relationship between race, culture, and reflection: how, they want to know, can students tap the reflective resources of home cultures in the work of the academy? And not least, Doug Hesse, addressing the essay, asks about the role of reflection as genre and about the essay's distinctive features exhibiting and supporting reflection. 
And yet, there are themes crossing many of these interests and questions. Thought of as tags, the topics addressed here include:

\section{REFLECTION AND PORTFOLIOS}

Michael Neal; Cathy Leaker and Heather Ostman; Jeff Sommers;

Elizabeth Clark; Naomi Silver

\section{REFLECTION AND FACULTY DEVELOPMENT}

Pamela Flash; Christina McDonald

\section{REFLECTION AND RACE, DIVERSITY AND LANGUAGE}

Cathy Leaker and Heather Ostman; Bruce Horner; Asao Inoue and

Tyler Richmond; Elizabeth Clark; Christina McDonald

\section{REFLECTION AND CONVERSATION, ESPECIALLY AS CONNECTED}

TO MAKING KNOWLEDGE

Pamela Flash; Kevin Roozen; Christina McDonald

\section{REFLECTION AND GENRE}

Jeff Sommers; Elizabeth Clark; Michael Neal; Doug Hesse

\section{REFLECTION AND COMPOSING}

Jeff Sommers; Elizabeth Clark; Cathy Leaker and Heather Ostman;

Doug Hesse

\section{REFLECTION AND TEACHER CHANGE}

Jeff Sommers; Elizabeth Clark

\section{REFLECTION AND TRANSFER OF WRITING KNOWLEDGE}

AND PRACTICE

Anne Beaufort; Kara Taczak and Liane Robertson

\section{REFLECTION AND SITES OF LANGUAGE AND IDENTITY}

Bruce Horner; Asao Inoue and Tyler Richmond; Jeff Sommers;

Elizabeth Clark; Cathy Leaker and Heather Ostman

\section{REFLECTION AND DIGITAL MULTIMODALITY}

Elizabeth Clark; Michael Neal; Naomi Silver; Christina McDonald

\section{REFLECTION AND TENSION}

Asao Inoue and Tyler Richmond; Christina McDonald; Pamela Flash;

Cathy Leaker and Heather Ostman

\section{THE CHAPTERS WITHIN}

The arrangement of the chapters tells yet another narrative, invents another way to think about reflection. Beginning with the classroom, 
A Rhetoric of Reflection both provides field-specific context for reflection and outlines promising practices. In "Reflection: The Metacognitive Move towards Transfer of Learning," Anne Beaufort identifies reflection in writing curricula as essential in fostering transfer of learningbut observes that by itself, reflection is not sufficient to foster transfer. Summarizing key theories on transfer of learning, including the need for repeated application of learning in addition to reflection for transfer to occur, Beaufort provides examples from her own teaching showing how she designs writing course curricula that include application and reflection. Also classroom oriented and interested in transfer of writing knowledge and practice, Kara Taczak and Liane Robertson, in chapter 3, report on the role of reflection in a specific curriculum, on the Teaching for Transfer curriculum (TFT), and on that curriculum's efficacy. In "Reiterative Reflection in the Twenty-First-Century Writing Classroom: An Integrated Approach to Teaching for Transfer," Taczak and Robertson document their claim that reflection promoting transfer is of a very specific kind: "Reflection must serve as both process and product," they say, and as "theory and practice." In addition, these authors focus on the way reflection needs to be incorporated throughout a course, a point of interest to Jeff Sommers as well-in their view, in reiterative, intentional, and systematic ways so that students become active and engaged reflective practitioners. As important, Taczak and Robertson report on two studies demonstrating that without such an approach to reflection, students are unable to identify what it is they have learned and are thus less able to tap that learning for future use.

A Rhetoric of Reflection then turns to assessment, another site of reflective practice, beginning with Michael Neal's consideration of the role of reflection in portfolio assessment. In "The Perils of Standing Alone: Reflective Writing in Relationship to Other Texts," Neal considers two issues critical to reflection on the context of assessment: (1) challenges leveled at reflective writing as a form of self-assessment and (2) the relationship of reflection to composing and to the other texts inside a portfolio. In taking up these issues, Neal is guided by two questions: What are the relationships between reflective writing and other artifacts within a portfolio? and What-if any-value remains in guiding students into specific reflective writing activities, either for teaching and learning or for the purposes of writing assessment? In considering these questions, Neal argues that reflection inside a portfolio contains a series of implicit arguments that must be supported by the accompanying artifacts in order to be valid; claims without evidence, he argues, are mere sentiments, while evidence without claims lacks self-awareness. In 
"Reflecting Practices: Competing Models of Reflection in the Rhetoric of Prior Learning Assessment," Cathy Leaker and Heather Ostman also consider the relationship of reflection to the making of claims, and to the making of knowledge, in an assessment context. Building on their 2010 College Composition and Communication essay examining the role of reflection in the context of prior learning assessment (PLA), Leaker and Ostman provide a taxonomy of reflection operating in the PLA context, which is designed to help students receive college credit for prior learning. The first, exchange, is oriented to predefined standards; the second, reflective-rhetorical transfer, is keyed to the use of reflection to narrate and theorize experiential learning as a form of academically credited learning; and the third, the most progressive, responsive reflection, engages both students and assessors in a coconstruction of both knowledge and assessment. In addition, Leaker and Ostman consider the various kinds of reflective knowledge, especially that created by participants in communities of color, that the most agentive PLA practices-rhetorical reflection and responsive reflection-may be excluding.

The second section of A Rhetoric of Reflection addresses the relationships among reflection, language, and difference: Bruce Horner's chapter, "Reflection-Action, Cross-Language Literacy, and Language Dispositions," opens it. Drawing in part from critical pedagogy as well as from scholarship in literacy and language, Horner theorizes how cross-language work can be not only the occasion but also the model for reflection-action in writing as, simultaneously, a language disposition and an ongoing, always emergent process. In this model of reflection, translinguality is inherently reflective. Moreover, Horner argues, such a view of reflection points to possible alignments between the development of such a disposition and models of learning transfer in cross-genre and cross-disciplinary work. Also focusing on language, Asao Inoue and Tyler Richmond study the reflective practices of Hmong students, learning in particular from four young Hmong women about how and why they reflect as they do. In "Theorizing the Reflection Practices of Hmong College Students: Is Reflection a Racialized Discourse?" Inoue and Richmond also compare the differences between Hmong students' reflective practices and those discussed in the literature on reflection, in the process considering the roles that culture, gender, and race can play in reflective practice. Based on their work with these students, Inoue and Richmond advise faculty to attend to the hidden assumptions that may be informing our use of reflection, which, they suggest, tend to ignore the possible racialized nature of the discourse of student reflection assigned and expected in US writing classrooms. 
The next section focuses on the relationship between reflection and media. Elizabeth Clark begins the section, noting the shift in pedagogical reflective practices that her teaching has taken, from print to digital multimodality. Clark begins her account, "From Selfies to SelfRepresentation in Electronically Mediated Reflection," with a meditation on the role of social media in students' lives today, in part to contrast that use of social media with a reflective use, in part to assure faculty that the two are different, that reflection is not merely a selfie exercise. What Clark appreciates about social media is their inclusion of multiple and differentiated contexts, a multiplicity she finds crucial for students' learning, and toward demonstrating what this learning looks like, she shares with us two reflective accounts explaining two very different learning situations. In presenting these, Clark is also arguing that reflection should provide for ambiguity and defer closure. Naomi Silver shares Clark's interest in the relationship of reflection and media; her focus in "Digitally Mediated Reflection: New Affordances, New Challenges" centers on what she calls a "reflective practicum," a space for new possibilities for digitally mediated reflection on writing. More specifically, in the chapter, Silver addresses and illustrates new topics for reflection and new ways to reflect in digital environments. Given that digital spaces open up many new avenues for and modes of reflection on writing- "with more genres than ever before to reflect on, more ways to compose, more tools and modes for reflection (e.g., screencasting or audio commentary), more ways to orchestrate collaborative and public reflection, and more opportunities for students and/as researchers to perform data-driven reflection on writing via versioning, histories, metadata, and the like"there are, as Silver demonstrates, both opportunities and challenges. At bottom, however, her claim is that digitality, precisely because of its multiple affordances, offers radically new possibilities for reflective practice.

In the fourth section of A Rhetoric of Reflection, "Reflective Conversations outside the Writing Classroom," Christina McDonald, Pamela Flash, and Kevin Roozen help us appreciate the social, dialogic nature of reflection. McDonald, in "Toward Defining a Social Reflective Pedagogy for ePortfolios," argues that ePortfolios, used within the framework of a processcentered pedagogy of reflective learning in a general education class, facilitate students' learning about culture by enabling them to construct new meaning from their experiences. Moreover, essential to this learning is a reflective pedagogy engaging students in multiple forms of reflection (e.g., reflection-in-action, constructive reflection, reciprocal reflection), in writing reflective "tags," in posting artifacts, and in responding to each other's ePortfolios throughout the semester. Pamela Flash, also 
venturing outside of the writing classroom, considers the role of reflective conversations in changing teaching practices inside a writing across the curriculum (WAC) program. In "From Apprised to Revised: Faculty in the Disciplines Change What They Never Knew They Knew," Flash relies on two questions to guide her consideration of reflective practice as a mechanism for change in WAC. First, might static, habitually reinforced conceptualizations of writing and writing instruction become animated and useful were faculty groups to engage in an ongoing series of reflective discussions about both? And second, how sustainable are these reflective practices given their diverse curricular settings? In taking up these questions, Flash draws on an array of data to make her case that faculty reflection motivates new understandings about and definitions of writing and subsequent curricular reform. Kevin Roozen, in "Reflective Interviewing: Methodological Moves for Tracing Tacit Knowledge and Challenging Chronotopic Representations," returns us to the student view as he considers another context for reflection, that of the one-toone interview with students about their literate histories and activities. As context for his own argument, Roozen outlines different forms of reflective interviewing: discourse-based interviews, process-based and practice-based interviews, and screen capture and video replay. Then Roozen outlines the fourth, reflective interviews, explaining how this methodological approach has contributed a good deal of what we currently understand about what writing, how it works, and how it might best be studied and taught.

Genre, another dimension of reflection, provides the theme of the book's last section, with its two contributions pointing in two directions. Jeff Sommers begins this section with his "Reflecting on Reflection: The Writer's Memo Twenty-Five Years Later," an essay reviewing the changing situatedness of the memo: Sommers moves from the original practice of simply assigning the memo to developing an implicit curriculum locating reflection as both a theory and a practice, including providing a rationale for reflection and the memo; sharing models of it at two points in the term; and encouraging students to see in the memo evidence they might cite in their longer reflective essays. As important, in this discussion Sommers teases out the two-pronged effects of the memo as genre: its effects on students and its effects on teachers evaluating students' writing. Then Doug Hesse, in "Reflecting and Essaying: Genre Features, Authors' Practices, and Implications for Others," considers reflection in the context of the personal essay, a reflection he identifies as "the necessary engine of the personal essay." More specifically, Hesse's chapter explores the role of reflection in the 
personal essay from two different perspectives: how it serves as a generative and critical force for authors and how it serves as an instructive and aesthetic force for readers. Drawing on multiple materials published in Fourth Genre, Hesse reminds us of the value of understanding reflection through the lens of practicing authors and of works designed for engagement and enjoyment as well as for intellectual growth. As important, he reminds us of how these writers also engage reflectively, mapping what they understand through the intersection of self, experience, and the world.

And in the last chapter, in a synthesis of what the earlier chapters have offered, I pursue the rhetoricity of reflection, the idea that reflection is rhetorical, by which I mean that a primary function of reflection is to make a kind of meaning and a kind of knowledge, one animated by attending, one located at the intersection of the personal and the intellectual, a knowledge that cannot be made without working at and inside this combination of contexts. That knowledge can take many forms: as these chapters suggest, reflection has been understood to make many, and many kinds of, contributions to writing and to learning more generally-among them, helping students transfer writing knowledge and practice from one site to another; providing students with a mechanism, in print and other media, for documenting learning; and, when prepared ethically, making available to reviewers a unique source of data for understanding how a student's learning has proceeded and progressed. At the same time, reflection is situated; it thus functions differentially according to context, purpose, and person; among those purposes are faculty development and research, and among its modalities are explicit directions and thoughtful and exploratory conversations. What we also see plotted in this third generation of reflection, however, is a widening epistemology, one encompassing, paradoxically, both clear articulation and a kind of Burkean ambiguity, with both articulation and ambiguity providing resources for a reflection that is rhetorical.

\section{References}

Ambrose, Susan A., Michael W. Bridges, Michele DiPietro, Marsha C. Lovett, Marie K. Norman. 2010. How Learning Works. San Francisco: Jossey Bass.

Anson, Chris. 1994. "Portfolios for Teachers: Writing Our Way to Reflective Practice." In New Directions in Portfolio Assessment, ed. Laurel Black, Donald A. Daiker, Jeffrey Sommers, and Gail Stygall, 185-200. Portsmouth, NH: Heinemann.

Bakhtin, M. M. 1981. The Dialogic Imagination: Four Essays. Ed. Michael Holquist. Trans. Caryl Emerson and Michael Holquist. Austin: University of Texas Press.

Beaufort, Anne. 2007. College Writing and Beyond: A New Framework for University Writing Instruction. Logan: Utah State University Press. 
Belanoff, Pat. 2001. "Silence: Reflection, Literacy, Learning, and Teaching." College Composition and Communication 52 (3): 399-428.

Brookfield, Stephen. 1995. Becoming a Critically Reflective Teacher. San Francisco: JosseyBass.

Bransford, John D., James W. Pellegrino, and M. Suzanne Donovan, eds. 2000. How People Learn: Brain, Mind, Experience, and School: Expanded Edition. Washington, DC: National Academies Press.

Butler, D. L. 1998. "The Strategic Content Learning Approach to Promoting SelfRegulated Learning: A Report of Three Studies." Journal of Educational Psychology 90: 682-97.

Camp, Roberta. 1992. "Portfolio Reflections in Middle and Secondary School Classrooms." In Portfolios in the Writing Classroom, ed. Kathleen Blake Yancey, 61-80. Urbana, IL: NCTE.

Conway, Glenda. 1994. "Portfolio Cover Letters, Students' Self-Presentation, and Teachers' Ethics." In New Directions in Portfolio Assessment: Reflective Practice, Critical Theory, and Large-Scale Scoring, ed. Donald A. Daiker and Laurel Black, Donald A Daiker, Jeffrey Sommers, and Gail Stygall, 83-92. Portsmouth, NH: Boynton/Cook.

Dewey, John. 1910. How We Think. Boston: Heath.

Dewey, John. 1916. Democracy and Education. New York: Macmillan.

Di Stefano, Giada, Francesca Gino, Gary Pisano, and Bradley Staats. 2014. "Learning by Thinking: How Reflection Aids Performance.” Harvard Business School Working Paper No. 14-093. http://dx.doi.org/10.2139/ssrn.2414478.

Emmons, Kimberly. 2003. "Rethinking Genres of Reflection: Student Portfolio Cover Letters and the Narrative of Progress." Composition Studies 31 (1): 43-62.

"A Fresh Look at Student Engagement." 2013. National Survey of Student Engagement. Bloomington: Indiana University School of Education.

Gawande, Atul. 2002. Complications: A Surgeon's Notes on an Imperfect Science. New York: Holt/Picador.

Jung, Julie. 2011. "Reflective Writing's Synecdochic Imperative: Process Descriptions Redescribed." College English 73 (6): 628-47.

Leaker, Cathy, and Heather Ostman. 2010. "Composing Knowledge: Writing, Rhetoric, and Reflection in Prior Learning Assessment." College Composition and Communication 61 (4): 691-717.

National Survey of Student Engagement (NSSE). 2014. Bringing the Institution into Focus: Annual Results. Bloomington, IN: Indiana University Center for Postsecondary Research.

Perl, Sondra. 1980. "Understanding Composing." College Composition and Communication 31 (4): 363-70. http://dx.doi.org/10.2307/356586.

Pianko, Sharon. 1979. "Reflection: A Critical Component of the Composing Process." College Composition and Communication 30 (3): 275-78. http://dx.doi.org/10.2307 /356394.

Pintrich, P. R. 2000. "The Role of Goal Orientation in Self-Regulated Learning." In Handbook of Self-Regulation, ed. M. Boekaerts, P. R. Pintrich, and M. Zeidner, 451-502. Burlington, MA: Elsevier Academic Press.

Schon, Donald A. 1987. Educating the Reflective Practitioner: Toward a New Design for Teaching and Learning in the Professions. San Francisco: Jossey-Bass.

Scott, Tony. 2005. "Creating the Subject of Portfolios: Reflective Writing and the Conveyance of Institutional Prerogatives.” Written Communication 22 (1): 3-35. http://dx.doi.org/10.1177/0741088304271831.

Silver, Naomi. 2013. "Reflective Pedagogies and the Metacognitive Turn in College Teaching." In Using Reflection and Metacognition to Improve Student Learning: Across the Disciplines, Across the Academy, ed. Matthew Kaplan, Naomi Silver, Danielle LaVaqueManty, and Deborah Meizlish, 1-18. Sterling, VA: Stylus. 
Sommers, Jeffrey. 1988. "Behind the Paper: Using the Student-Teacher Memo." College Composition and Communication 39 (1): 77-80. http://dx.doi.org/10.2307/357824.

Sommers, Jeff. 2011. "Reflection Revisited: The Class Collage." Journal of Basic Writing 30 (1): 99-129.

Thelin, William H. 1994. "The Connection between Response Styles and Portfolio Assessment: Three Case Studies of Student Revision." In New Directions in Portfolio Assessment: Reflective Practice, Critical Theory, and Large-Scale Scoring, ed. Laurel Black, Donald Daiker, Jeffrey Sommers, and Gail Stygall, 113-25. Portsmouth, NH: Boynton/Cook Heinemann.

White, Edward M. 2005. "The Scoring of Writing Portfolios: Phase 2." College Composition and Communication 56 (4): 581-600.

Winne, P. H., and A. F Hadwin. 1998. "Studying as Self-Regulated Engagement in Learning." In Metacognition in Educational Theory and Practice, ed. D. Hacker, J. Dunlosky, and A. Graesser, 277-304. Mahwah, NJ: Lawrence Erlbaum.

Yancey, Kathleen Blake, ed. 1992. Portfolios in the Writing Classroom: An Introduction. Urbana, IL: NCTE.

Yancey, Kathleen Blake. 1998. Reflection in the Writing Classroom. Logan: Utah State University Press.

Yancey, Kathleen Blake. 2009. "Reflection and Electronic Portfolios: Inventing the Self and Reinventing the University." In Electronic Portfolios 2.0, ed. Darren Cambridge, Barbara Cambridge, and Kathleen Blake Yancey, 5-17.

Yancey, Kathleen Blake, Liane Robertson, and Kara Taczak. 2014. Writing across Contexts: Transfer, Composition, and Sites of Writing. Logan: Utah State University Press.

Yancey, Kathleen Blake. Forthcoming. "Tagmemics *and* the Sex Pistols: Current Promising Approaches to Individual and Programmatic Writing Assessment." In Perspectives on Academic and Professional Writing in an Age of Accountability, ed. Shirley Logan and Wayne Slater. Carbondale: Southern Illinois University Press.

Zimmerman, B. J. 2000. "Attaining Self-Regulation: A Social Cognitive Perspective." In Handbook of Self-Regulation, ed. Boekaerts, M, Pintrich, P R and Zeidner, M. San Diego, CA: Academic Press. 